\title{
The current decline in oil: Investment and macroeconomic considerations
}

\author{
Daniel A Peters MD MBA FRCSC ${ }^{1}$, Douglas R McKay MD MBA FRCSC ${ }^{2}$
}

$\mathrm{O}^{\prime}$ ver the past several months, the price of oil has declined precipitously. From a high of $\$ 145$ per barrel in July of 2008 , the price of oil has now declined to below $\$ 50$ per barrel at the time of this writing. The correlation with the performance of the Canadian market has been striking. Current news reports focus on the decline in Canadian securities performance as a reflection of weakness in the oil market. Given the cyclical nature of the securities market and the commodities market, questions arise as to whether the price of oil has reached its nadir and whether the current environment represents an opportunity to purchase oil-based products as part of a value-accretion strategy.

\section{How is oil traded}

Oil is is regulated by the Commodity Futures Trading Commission and is usually bought as a derivative product. In most cases, oil is purchased as a future contract. This contract entitles the purchaser to buy the security at a future date at a specified price. It is typically traded by two broad classes of investors. The largest class has interests in the oil industry. They are trading as a hedge against price fluctuations. Airlines, manufacturers and others who use oil as a factor of production use such contracts as a means of providing predictable supply at predictable prices. The second class of individuals who purchase such contracts are speculators who seek to profit from fluctuations in market price. In most cases, such speculation is confined to the contracts themselves and no delivery is taken of the commodity.

\section{How is the price of oil determined?}

There are three primary factors that influence the price of oil. The first is market demand. Energy demand is often conceived as a proxy for economic and manufacturing activity within the economies of various countries. Aggregate output has begun to slow worldwide. While gross domestic products continue to rise slowly, the rapid growth witnessed in some countries has slowed. This has been especially true in China, where demand for oil has plateaued. As economic growth has been curtailed, the effect is a reduction in demand for energy and for oil. In more developed countries, there has been a shift toward alternative energy production, thus decreasing demand for carbon-based energy. Such reduction in demand has a negative effect on price.

Supply is the second determining factor. Supply is often determined by the cost of production in the short and long term. The cost of production varies depending on the cost of extraction and processing. The cheapest cost of production is in Saudi Arabia and Libya, where production can be as low as $\$ 5$ per barrel. However, production costs reach a zenith of $\$ 90$ per barrel in some oil sands developments. In the short term, supply can be adjusted to reflect immediate demand. However, this becomes more complicated in the long term. Decisions regarding infrastructure are made in anticipation of future prices. Once committed, much of this infrastructure is built regardless of the current price. Decisions regarding operations occur at the margins, thus promoting production once large capital costs have been incurred. The overall effect has been a significant increase in supply. Large investments in infrastructure have been made by 'fracking' firms. Fracking in the United States has significantly increased the supply of domestic oil. While the United States does not export oil to any significant degree, it has curtailed its import as the result of domestic production. Supply has also expanded as the result of geopolitical factors. The current conflicts in Iraq and Libya have not curtailed production to the extent expected, thus increasing global supply. Finally, there has been no move by the Organization of the Petroleum Exporting Countries to reduce production by its members to stabilize price. They are continuing to produce in an effort to maintain market share. The cumulative effect has been a highly significant increase in supply.

The third ingredient is deemed by most experts to be market sentiment. As the name implies, there is very little certainty associated with these fluctuations. While market fundamentals may be held constant, in some circumstances, volatility may result from increased speculation and macroeconomic predictions. The source and result of these sentimental shifts remains elusive and exceedingly difficult to predict.

\section{STRATEGIES FOR INVESTING IN OIL}

The precipitous decline in the price of oil has led many speculators to conclude that the time is approaching at which investment in this commodity would be warranted. We have been asked by many in our profession whether this current decline represents an opportunity for investment. While short-term fluctuations are difficult to predict, value accretion of energy appears to have long-term merit. Difficulties arise in assessing the timing of such a purchase and the method by which this should be accomplished.

There are two principle mechanisms for investing in oil. The first is to trade securities that closely track the price of oil. Such securities would include energy (or oil) exchange traded funds. The second strategy is to invest in securities of energy producers. Such investments may be strongly influenced by the price of an underlying commodity but would not be completely correlated. Of course, you could buy the commodity itself, but this may require delivery and most of us do not have a place to store barrels of oil.

The most accessible vehicle for tracking the price of oil is in exchange-traded funds (ETFs). Oil ETFs consists of futures, options and forward contracts for different types of oil and gas. There are multiple such ETFs. The largest of such funds is the United States Oil ETF. Other examples include the United States 12 Month Oil Fund ETF, the United States Heating Oil Fund ETF and the Goldman Sachs Crude Oil Total Return ETN. There are multiple other funds that permit the investor track the performance of oil and other petroleum products.

Investing in such funds requires a view of the direction of price. If one anticipates that the price will increase, the strategy would be to go long on these assets. However, many economists continue to argue that oil- and petroleum-based products may experience further declines in value. Such a worldview would require one of two strategies. The first would be to short the aforementioned funds. This requires a brokerage capable of extending credit for the security. Often this requires collateral and margin accounts. A more straightforward strategy would be to use an inverse oil ETF. These are ETFs that track

${ }^{1}$ Division of Plastic Surgery, Department of Surgery and Telfer School of Management, University of Ottawa, Ottawa; ${ }^{2}$ Division of Plastic Surgery, Department of Surgery, Queen's University, Kingston, Ontario

Correspondence: Dr Daniel A Peters, University of Ottawa, PO Box 2013, 1053 Carling Avenue, Ottawa, Ontario K1Y 4 E9.

Telephone 613-795-5555, fax 613-761-4025, e-mail dannypeters1@gmail.com 
the performance of the underlying commodity but yield returns that are the inverse of those returns. These serve the same strategic purpose as shorting an ETF, but are more accessible for investors with account or margin restrictions.

The above strategies require exposure to the underlying commodity and, therefore, require a specific worldview. While supply and demand in the short and long term may be predictable, the unknown effects of market sentiment are obscure. This leads to uncertainty. Such uncertainty can be mitigated in multiple fashions. One strategy to consider is an investment in an energy producer. Such an investment reflects the value of the underlying commodity but also other effects introduced by the business.

Energy producers are evaluated similar to most other securities on the basis of value accretion and dividend distributions. Most energy companies have a long historical record of strong dividend distributions. Therefore, in considering whether they are profitable investments, two considerations should be considered. The first is yield. This is a metric, which reflects the value that has accrued in the stock price. This is the most basic of analyses in which the price at which the security is bought is deducted from its selling price, discounted to present value and the remainder yields profit. However, in considering the value of a dividend dispensing security another metric should be considered. This metric is termed yield on cost. This is the cash return that accrues to the investor as a result of buying and holding the stock. Traditionally, the dividend return from energy producers has been relatively stable and secure. For example, the 10-year yield on cost for Exxon Mobil is 7.6\%. This reflects a relatively strong return on investment merely as a result of dividend distributions.

The decision regarding an investment in such companies must incorporate the value of the underlying commodity but should not be constrained by the price of oil. There are many ways in which producers can be profitable in an environment of low oil prices. In some instances, the focus of the business can be shifted from one aspect of production to another. For example, if oil extraction becomes less profitable, profits may be stabilized from contributions in the refining business.

Of course, it is also possible to be long or short on producers. An anticipated decline in the value of producers would suggest a short strategy. Combinations of strategies could also be incorporated. For example, one could be long on a producer with a hedge using an inverse ETF for oil or petroleum products. A hedge type strategy should be considered in circumstances in which uncertainty predominates.

\section{OVERALL INVESTMENT CONSIDERATIONS}

The current extreme volatility in the price of oil may reflect underlying economic shifts in demand in supply. This may portend a period of depressed prices followed by cyclical increases. These extreme fluctuations may represent an opportunity for investment. Furthermore, these fluctuations illustrate the principles by which uncertainty can be mitigated and modulated to maximum benefit. 